\title{
TREATMENT GOALS ACHIEVED AMONG HYPERTENSIVES AT THE B/A REGIONAL HOSPITAL IN SUNYANI, GHANA.
}

\author{
FRANCIS FORDJOUR ${ }^{1}$, PAUL SODZI ${ }^{1}$, PHILEMON BAAH ${ }^{2}$
}

${ }^{1}$ Department of Pharmaceutical Sciences, Sunyani Technical University, P. 0. Box 206, Sunyani, Ghana. ${ }^{2}$ Department of Mathematics and Statistics, Sunyani Technical University, P. 0. Box 206, Sunyani, Ghana. Email: fransfordcudjoe@yahoo.co.uk

Received: 09 July 2020, Revised and Accepted: 09 September 2020

\section{ABSTRACT}

Objective: The objective of the study was to assess the current success rate of hypertensive patients in achieving blood pressure (BP) treatment goals and to investigate the extent of the consistency in the control of BP following initial achievement.

Methods: At the hypertension clinic of the B/A Regional Hospital in Sunyani, Ghana, the current BP of 400 sampled patients, aged 35-100 years was measured. In addition, a retrospective review of nine successive BPs previously recorded in patients' medical histories was done.

Results: Of the 400 patients, women constituted $71.75 \%$. Hypertensives aged $\geq 60$ years represented $64.25 \%$ with the rest being $<60$ years. In $58 \%$ of patients, there were comorbidities. Adherence to clinic appointment was $54.50 \%$. Of the ten clinic visits, $20.30 \%$ of patients $<60$ years were adequately controlled of their BPs while those $\geq 60$ years achieved $33.80 \%$ control. In all, $29 \%$ of the 400 hypertensives met their treatment goals adequately. Consistency in maintaining a controlled BP at all times was achieved by $23.70 \%$ of the 400 patients. Regular visits to clinic was associated with adequate BP control $(\mathrm{p}<0.001)$ while comorbidity was not $(\mathrm{p}=0.122)$.

Conclusion: Treatment goals' achievement by hypertensives at the Regional Hospital in Sunyani, Ghana, was relatively low. Consistency in maintaining a controlled BP while on medication is poor. The lack of consistency in keeping a controlled BP may contribute to the increased cardiovascular deaths among hypertensives. Intensive mass education and treatment optimization are required to deal with treatment failures among patients.

Keywords: Hypertensives, Treatment goal, Treatment target, Controlled blood pressure, Consistency.

(C) 2020 The Authors. Published by Innovare Academic Sciences Pvt Ltd. This is an open access article under the CC BY license (http://creativecommons. org/licenses/by/4. 0/) DOI: http://dx.doi.org/10.22159/ajpcr.2020.v13i11.38991

\section{INTRODUCTION}

Hypertension accounts for the most frequent patient visit to the physician [1]. The blood pressure (BP) level in a hypertensive is a major prognostic determinant, and cardiovascular deaths (CVD) are typically associated with patients who are poorly controlled of their hypertension [2]. Therefore, the control of elevated BP is an important management goal.

Hypertensives $<60$ years whose BPs are maintained below 140/90 $\mathrm{mm} \mathrm{Hg}$ experience lower incidence of cardiovascular complications and death [3,4]. The Systolic BP Intervention Trial (SPRINT) suggests remarkable cardiovascular benefits from intensive BP control to systolic BP below $120 \mathrm{~mm} \mathrm{Hg}$ in non-diabetic hypertensives $\geq 50$ years [5].

To achieve better cardiovascular outcomes, patients' BPs ought to be persistently kept under control and this objective has been the driving force of both physicians and patients over the years. Even though more patients are receiving treatment for hypertension, the World Health Organization continues to report of cardiovascular diseases as the leading cause of death globally [6]. In 2016, the Ghana Medical Association lamented the alarming rate of CVD among adults over age 30 in Sub-Saharan Africa [7]. The Ghana Health Service reported a similar statistic in 2017 where hypertension related diseases were cited as the number one cause of death in the country in spite of most patients seeking treatment to control their BPs [8].

Monitoring the course of treatment of hypertensive patients could help determine their success rate as well as predicting their cardiovascular benefits which could translate into increased survival or otherwise. In countries such as Cuba, England, USA, Canada, and Japan, treatment outcomes of hypertensives are monitored periodically, and such findings serve as the basis for optimizing treatment plans to deal with treatment failures [9-11]. In 2018, a study based on national demographic data in Ghana indicated $23.8 \%$ hypertension control among patients, and in the middle belt, $41.3 \%$ control was reported by another study in 2019 [12,13]. In spite of an improvement in BP control reported in Ghana, mortalities due to stroke and myocardial infarction continue to be a burden in the country, questioning the consistency of treated patients in keeping their BPs at target. While maintenance of consistent control of BP is generally accepted as critical to preventing hypertensive patients from developing complications, there is a dearth of studies in Ghanaian Hospitals to highlight this fact. It is against this background that we aimed to assess and report on the success rate of treated hypertensive patients, and also investigate the extent of consistency in achieving BP treatment targets at a Regional Hospital in Ghana. Specifically, we aimed to determine the proportion of hypertensives under medication who achieve their treatment goals, and to investigate the extent of the consistency in the control of BP following initial achievement of treatment targets. Our long-term goal was to provide evidence-based feedback on treatment outcomes to health-care providers about hypertensives, specifically, whether hypertensive patients at the Sunyani Regional Hospital in Ghana had their high BPs adequately and consistently controlled long enough to accrue the benefits of a healthy cardiovascular life or otherwise.

\section{METHODS}

\section{Study site}

The study was carried out at the B/A Regional Hospital located in Sunyani, the capital city of the Bono Region of Ghana. The Hospital is a 350-bed capacity secondary health facility staffed with the various health professionals to the specialist grades. It is the referral hospital serving all district health facilities in the Bono Region. The region lies on the western part of the middle belt of Ghana sharing borders with Savanna Region to the north, Bono East Region to the east, Ahafo 
Region to the south, and neighboring Ivory Coast to the west. The major economic activity of the region is farming.

\section{Study design}

A cross-sectional design was used to review the BP recordings of 400 hypertensive patients selected at random between July 2019 and November 2019. A retrospective data collection was done starting from currently measured BPs to previously recorded BPs of patients aged 35-100 years using a designed data sheet.

\section{Data collection}

The collected data included patient's gender, current age, weight, employment status, hospital review dates, review intervals, comorbidities, recorded BPs, as well as antihypertensive medications prescribed. Data collection was done on hypertension clinic days at the hospital after randomly selected patients have had their BPs checked by experienced registered nurses. A patient was allowed to sit and rest for at least $5 \mathrm{~min}$ in a relaxed manner with feet resting on floor and uncrossed. Using an appropriate cuff sized mercury sphygmomanometer; the BPs of patients were measured. The BP values used were the averages of two successive $\mathrm{BP}$ readings. The currently measured BP; together with nine previously recorded BPs on successive hospital visits, in the medical histories of patients amounting to ten BP readings were retrospectively captured.

\section{Inclusion and exclusion criteria}

Patients were considered for inclusion if they have been diagnosed by a physician to be hypertensive in the past 2 years or more and have been coming for review and medication refill. Pregnant women were not included in the study, as well as patients with missing portions of data from their records.

\section{Definitions}

Hypertension and its treatment modalities were based on the 2017 Standard Treatment Guidelines of Ghana and that of the Eighth Joint National Commission Guidelines (JNC 8) [14,15]. Patients were categorized into age $<60$ years or $\geq 60$ years. A persistent BP of $140 / 90 \mathrm{~mm} \mathrm{Hg}$ or more was diagnostic for patients under 60 years as well as diabetic mellitus patients, while that of $150 / 90 \mathrm{~mm} \mathrm{Hg}$ or above was diagnostic for patients $\geq 60$ years. Treatment targets were met if hypertensive patients below 60 years or 60 years and above on treatment achieved both systolic and diastolic BP values below $140 / 90 \mathrm{~mm} \mathrm{Hg}$ or $150 / 90 \mathrm{~mm} \mathrm{Hg}$, respectively.

A patient's hypertension was considered adequately controlled if out of the ten different hospital reviews, the measured BP met the treatment goal on at least nine occasions. A patient was deemed moderately controlled if the patient's BP target was achieved on seven to eight out of the ten occasions. Patients' hypertension were designated as fairly controlled if they met their BP goal on five to six out of ten visits, whereas those patients who achieved their target on four or less occasions were considered poorly controlled.

\section{Statistical analysis}

Using SPSS version 20 , the collected data were coded and analyzed. The mean \pm standard deviations (SD) of age, weight, and systolic and diastolic values were computed. Frequencies and percentages of patients' variables were then tabulated. Two age groupings of patients were used: $<60$ years with BP target of $<140 / 90 \mathrm{~mm} \mathrm{Hg}$, or $\geq 60$ years with a BP target of $<150 / 90 \mathrm{~mm} \mathrm{Hg}$. The number of times patients' measured BP met the treatment target out of the ten visits was calculated in percentages and a simple percentile categorization was used to indicate patient's level of BP control. Based on the percentage scores, patients were classified as adequately controlled (90-100\%), moderately controlled (70-80\%), fairly controlled (50-60\%), or poorly controlled $(\leq 40 \%)$. However, consistency in maintaining hypertension control was based on a $100 \%$ control rate. Pearson's Chi-square test was used to determine the association between regular clinic reviews, presence of comorbidity, and adequately controlled hypertension among patients using a statistically significant $\mathrm{p} \leq 0.05$ at $95 \%$ confidence interval.

\section{Study approval}

Approval to conduct this study at the site was granted by the Medical Directorate and the Institutional Research Committee of the B/A Regional Hospital in Sunyani, Ghana. The study was conducted under high ethical standards, and identifying personal patient information (e.g., name and address) were omitted to maintain patient privacy.

\section{RESULTS}

The study consisted of 400 hypertensive patients enrolled at the hypertension clinic. Men constituted $28.25 \%(n=113)$ of the study participants while women formed $71.75 \%(\mathrm{n}=287)$. The age range was $35-100$ years with mean \pm SD age of $64 \pm 11$.9. Patients aged 60 years and above $(64.25 \%)$ were more than those below 60 years. The mean \pm SD weight was $68 \pm 14.7 \mathrm{~kg}$ ( 40 to $120 \mathrm{~kg}$ ). A little above a third of the patients $(38.5 \%)$ have had education beyond the second circle level. Of the 400 patients, $58 \%(n=232)$ had comorbid conditions. Diabetes $(28 \%)$, poststroke (8\%), peripheral neuropathies (6.25\%), and dyslipidemia (6\%) were the predominant comorbid conditions identified. Patients were reviewed by physicians at scheduled intervals of 4 weeks, 8 weeks, or 12 weeks with $90.25 \%$ of them coming for review every 8 weeks. Fifty-four percent of patients adhered to clinic appointment dates (Table 1).

From the ten different clinic visits among all the 400 patients, the mean \pm SD for systolic BP $(\mathrm{mm} \mathrm{Hg})$ was $133 \pm 18.8 \mathrm{~mm} \mathrm{Hg}(80-220 \mathrm{~mm}$ $\mathrm{Hg}$ ) while the diastolic pressure was $77 \pm 12.3 \mathrm{~mm} \mathrm{Hg}(50-180 \mathrm{~mm} \mathrm{Hg})$.

Of the ten different clinic review dates, where the BPs of patients were checked, $20.3 \%(10.5+9.8)$ of patients $<60$ years with a BP target of $<140 / 90 \mathrm{~mm} \mathrm{Hg}$ achieved $90-100 \%$ target rate. For those 60 years with 150/90 mmHg as BP target, 33.8\% (13.2+20.6) scored a target of

Table 1: Patients' demographic profile

\begin{tabular}{|c|c|}
\hline Characteristics & n (\%) \\
\hline \multicolumn{2}{|l|}{ Gender } \\
\hline Men & $113(28.25)$ \\
\hline Women & $287(71.75)$ \\
\hline \multicolumn{2}{|l|}{ Age (years) } \\
\hline Men $<60$ & $34(8.5)$ \\
\hline Women $<60$ & $109(27.25)$ \\
\hline Men $\geq 60$ & $79(19.75)$ \\
\hline Women $\geq 60$ & $178(44.5)$ \\
\hline \multicolumn{2}{|l|}{ Occupation } \\
\hline Unemployed & $45(11.25)$ \\
\hline Formal employment & $55(13.75)$ \\
\hline Informal employment & $127(31.75)$ \\
\hline Retired & $56(14)$ \\
\hline Farming & $117(29.25)$ \\
\hline \multicolumn{2}{|l|}{ Presence of comorbidity } \\
\hline Yes & $232(58)$ \\
\hline No & $168(42)$ \\
\hline \multicolumn{2}{|l|}{ Type of comorbidity } \\
\hline None & $168(42)$ \\
\hline Diabetes mellitus & $112(28)$ \\
\hline Post-stroke & $32(8)$ \\
\hline Peripheral neuropathy & $25(6.25)$ \\
\hline Dyslipidemia & $24(6)$ \\
\hline Arthritis & $13(3.25)$ \\
\hline Heart failure & $11(2.75)$ \\
\hline Peptic ulcer & $6(1.5)$ \\
\hline Benign prostate hyperplasia & $4(1)$ \\
\hline Ischemic heart disease & $3(0.75)$ \\
\hline Asthma & $1(0.25)$ \\
\hline Arrhythmia & $1(0.25)$ \\
\hline \multicolumn{2}{|l|}{ Review interval (weeks) } \\
\hline 4 & $34(8.5)$ \\
\hline 8 & $361(90.25)$ \\
\hline 12 & $5(1.25)$ \\
\hline \multicolumn{2}{|l|}{ Clinic attendance } \\
\hline Regular & $218(54.5)$ \\
\hline Defaulter & $182(45.5)$ \\
\hline
\end{tabular}


90-100\% (Table 2). Again, for patients below 60 years, 10.5\% were consistently controlled of their BP on all the ten hospital visits while $13.2 \%$ of patients $\geq 60$ years achieved their target on all visits. Thus, only 23.7 $(10.5+13.2) \%(n=49)$ of the 400 patients were consistent in maintaining their BP at treatment targets at all times, as displayed by Table 2 .

Altogether, per our percentile categorization, 29\% $(n=116)$ of the patients were considered adequately controlled while 31.5\% $(n=126)$ were poorly controlled (Table 3).

Out of the 116 patients whose hypertension was adequately controlled, $25.9 \%(n=30)$ were men while $74.1 \%(n=86)$ were women. Of this adequately controlled group, $42.2 \%(n=49)$ had comorbid conditions managed concurrently of which diabetes patients formed 26 out of the 49. Overall, few diabetic patients, that is, $23.2 \%(n=112)$ were adequately controlled of their high BPs. From Pearson's Chi-square test, the presence of a comorbidity was not significantly associated $(\mathrm{p}=0.122$ ) with adequate hypertension control among the patients. However, regular clinic reviews was significantly associated $(\mathrm{p}<0.001)$ with adequate control of hypertension among patients.

Patients' prescribed antihypertensives assessment in Table 4 indicates that prescriptions with two antihypertensives were common. Calcium channel blockers specifically, nifedipine, or amlodipine combined with angiotensin-converting enzyme inhibitors (ACEIs) or angiotension receptor blockers (ARBs) such as lisinopril or losartan were medicines mostly prescribed.

\section{DISCUSSION}

We studied mostly an adult hypertensive population with an average age of 64 years, largely women, with most patients either engaged in

Table 2: BP targets achieved by patients from ten successive hospital visits

\begin{tabular}{|c|c|c|c|}
\hline \multirow[t]{2}{*}{ S. no. } & \multirow[t]{2}{*}{$\begin{array}{l}\text { No of times target was } \\
\text { achieved }\end{array}$} & $\begin{array}{l}\text { BP target: } \\
<140 / 90 \mathrm{mmHg} \\
\text { (<60 years) } \\
\end{array}$ & \multirow{2}{*}{$\begin{array}{l}\text { Target: } \\
<150 / 90 \mathrm{mmHg} \\
\text { ( } \geq 60 \text { years }) \\
\mathrm{n}(\%)\end{array}$} \\
\hline & & n (\%) & \\
\hline 1. & Ten out of ten reviews & $15(10.5)$ & $34(13.2)$ \\
\hline 2. & Nine out of ten reviews & $14(9.8)$ & $53(20.6)$ \\
\hline 3. & Eight out of ten reviews & $14(9.8)$ & $37(14.4)$ \\
\hline 4. & Seven out of ten reviews & $8(5.6)$ & $32(12.5)$ \\
\hline 5. & Six out of ten reviews & $13(9.1)$ & $17(6.6)$ \\
\hline 6. & Five out of ten reviews & $16(11.2)$ & $21(8.2)$ \\
\hline 7. & Four out of ten reviews & $12(8.4)$ & $15(5.8)$ \\
\hline 8. & Three out of ten reviews & 17 (11.9) & $17(6.6)$ \\
\hline 9. & Two out of 10 reviews & $14(9.8)$ & $11(4.3)$ \\
\hline 10. & One out of ten reviews & $14(9.8)$ & $12(4.7)$ \\
\hline 11. & None & $6(4.1)$ & $8(3.1)$ \\
\hline Total & & $143(100)$ & $257(100)$ \\
\hline
\end{tabular}

BP: Blood pressure

Table 3: Percentile categorization of level of BP control among patients

\begin{tabular}{llll}
\hline Level of control & $\mathbf{n}$ (men) & $\mathbf{n}$ (women) & $\mathbf{n}(\%)$ \\
\hline $\begin{array}{l}\text { Adequately controlled } \\
(90-100 \% \text { control rate) }\end{array}$ & 30 & 86 & $116(29)$ \\
$\begin{array}{l}\text { Moderately controlled } \\
(70-80 \% \text { control rate) }\end{array}$ & 25 & 66 & $91(22.75)$ \\
$\begin{array}{l}\text { Fairly controlled (50-60\% } \\
\text { control rate) }\end{array}$ & 20 & 47 & $67(16.75)$ \\
$\begin{array}{l}\text { Poorly controlled (0-40\% } \\
\text { control rate) }\end{array}$ & 38 & 88 & $126(31.5)$ \\
Total & 113 & 287 & $400(100)$ \\
\hline
\end{tabular}

the informal sector or farming activities. The majority of our patients (90.25\%) were reviewed at the clinic at 8 weeks intervals. Our data showed that almost half of the patients (45.5\%) were not adherent in keeping to their clinic appointment dates compared to lower findings of $20 \%$ among African-Americans in Maryland and $16.7 \%$ in Nigeria [16,17]. In our view, patients' farming activities could interfere with hospital attendance during farming seasons, and they were therefore, likely to postpone hospital review visits to engage in seed planting at their farms during the raining seasons. Hypertensive patients who failed to keep to appointments are likely to run out of medications, and medication holiday could cause a sudden rise in BP leading to complications and unwarranted hospital admissions. We found a significant association between regular hospital review and adequate BP control in patients which was at variance with an earlier report that BP was not related to appointment-keeping behavior [18].

Our major findings indicated a low level of BP control among hypertensives as well as a lack of consistency in maintaining a controlled BP by most patients. Overall, less than a third $(29 \%)$ of the patients had their hypertension adequately controlled. Our finding at the B/A Regional Hospital in Sunyani is relatively higher than a report (23.8\%) based on national demographic data in Ghana in 2018 but lower than what was found $(41.3 \%)$ in the middle belt of Ghana $[12,13]$. We believe our finding differed from the latter study, because of differences in the BP data used. Our study considered ten successive BP recordings from separate review dates, and we looked at the consistency in achieving BP targets over a period of almost 2 years instead of a 1 day average BP measurement used by other studies. Most of our patients had fluctuated BPs between control and uncontrolled at different clinic visits. Some had only systolic or diastolic values meeting the target at visits. We found only $23.7 \%$ of patients consistently maintaining their BPs at target at all hospital visits; an outcome lower than $42 \%$ reported among African Americans studied at Cook County [19]. The lack of consistency in keeping BP under control by most of our patients, could partly explain the reason why mortalities due to hypertensive heart diseases among Ghanaian is on the ascendancy, even though more patients are receiving treatment for their hypertension [8].

Among the different age groups, patients $<60$ years with a BP threshold of $140 / 90 \mathrm{~mm} \mathrm{Hg}$ were least controlled (Table 2), similar to outcomes in five European countries, Canada, and the United States in 2003 [20]. The European Study on Cardiovascular Risk Prevention and Management in Daily Practice (EURIKA) and DIALOUGE registry studies also reported lower rates of hypertension control generally among patients [21,22]. Comparatively, hypertension treatment outcomes were slightly better among African Americans in USA (52\%), patients in Ethiopia, (43.51\%), and those in Lebanon (61\%) in 2012, 2017, and 2018, respectively [19,23,24]. In general, hypertension control among patients of African descent has been poor compared to the other race. Established reasons mostly cited are poverty, poorly resourced health facilities, and systemic defects. Although cost of medications, medication or appointment non-adherence, and co-morbidities are some factors that may retard the treatment success of hypertension in African patients, strong attachment of most patients of African descent to religious beliefs could be an underrated contributory factor. It is common in the Ghanaian and other African media to hear or see fetish priests, the so-called "men of God" and unskilled herbal practitioners making claims of having a cure for stroke, hypertension, and other cardiovascular conditions. It is believed that the uneducated African hypertensives may interrupt their orthodox

Table 4: Antihypertensives assessed on patients' prescriptions

\begin{tabular}{ll}
\hline Number of antihypertensives per patient & $\mathbf{n}(\mathbf{\%})$ \\
\hline One antihypertensive & $126(31.5)$ \\
Two antihypertensives & $211(52.75)$ \\
Three antihypertensives & $55(13.75)$ \\
Four antihypertensives & $8(2)$ \\
Total & $400(100)$ \\
\hline
\end{tabular}


treatment, in search of spiritual healing professed by priests, and unskilled herbalists. Such patients may only return to the hospital after they have been debilitated by cardiovascular complications. Other patients may have low response rate because of self-medication using contraindicated substances such as non-steroidal anti-inflammatory drugs (NSAIDs) or high salty diets. These barriers have the potential to retard the successful treatment and control of hypertension among the black folks.

We found more females (71.75\%) attending hypertension clinic than their male counterparts in both age categories of patients, and of the adequately controlled patients (Table 3), there were more females $(29.97 \%)$ than males $(26.55 \%)$. This aligns with a study in which more women than men treated and controlled their high BPs [25]. Hypertension correlates positively with age and after age 60, more women are said to have increased prevalence of hypertension than men $[26,27]$. Our study participants were largely menopausal women, considering their average age of 64 years. And apart from poor eating habits, lack of exercises, and obesity, vascular dysfunction due to lack of estrogen in menopause might contribute to the high female hypertensive count at the clinic $[28,29]$. While suspecting that side effects of most antihypertensives, particularly erectile dysfunction in men who want to maintain their potency might prevent some from attending hypertension clinics, we also inferred that more women cared about their cardiovascular health than men hence the reason for more women taking the lead at the clinic [30].

Comorbidity was seen in more than half of the patients (58\%) in this study of which diabetes mellitus was the commonest $(28 \%)$. The presence of diabetes doubles the risk of cardiovascular complications in hypertensives [22]. Of all the patients (116) who attained adequate control of their hypertension, almost half (49) were comorbid patients of which diabetes mellitus formed a few (22.41\%) of the successful ones. From Pearson's Chi-square test, the presence of a comorbidity was not significantly associated $(\mathrm{p}=0.122)$ with adequate hypertension control among the patients studied although studies such as the EURIKA and DIALOUGE indicated poor hypertension control among diabetic hypertensives. Our finding probably differed because almost half of the adequately controlled patients had comorbidities. Few (8\%) of the patients in this study had already suffered from stroke and were going through secondary preventive therapies for post-stroke patients. This reiterates the fact that intensifying primary preventive therapies in comorbid hypertensive patients would be valuable in saving patients from early stroke incidents.

Although more than half $(52.75 \%)$ of the patients were on two antihypertensives as recommended by most guidelines, treatment outcomes were low [31-33]. Poor adherence to treatment regimen, side effect of antihypertensives, inefficacious medications, and failure of physicians to maximize medication doses could account for the low treatment success. Dose optimization in some patients and the use of triple therapies may be required in some patients to achieve BP targets.

\section{Study limitations}

This study was affected by some limitations. Data collection was largely retrospective and limited to hypertensives assessing care in only one Regional Health facility in Ghana making generalization of findings impossible. Few of the patients had arthritis and were treated with NSAID that could affect BP control.

\section{CONCLUSION}

BP treatment goals achieved by hypertensives at the B/A Regional Hospital in Ghana are relatively low. Consistency in maintaining a controlled BP while on medication is poor. The increased cardiovascular complications/death among hypertensives in the hospital may be due to a lack of consistency in keeping a controlled BP after initial achievements. Intensive mass media education, treatment optimization using efficacious medicines, and regular monitoring are required to deal with treatment failures among most hypertensives to decrease the risk of CVD.

\section{AUTHORS' CONTRIBUTIONS}

All the authors contributed in the conceptualization, conduct of the study, and preparation of the manuscript.

\section{CONFLICTS OF INTEREST}

The authors declare that there are no conflicts of interest regarding the publication of this paper.

\section{AUTHORS' FUNDING}

Authors declare that we did not receive any funding from any source in the conduct or publication of this article.

\section{ACKNOWLEDGMENTS}

The authors are grateful to the management of the B/A Regional Hospital in Sunyani for granting permission to use the hospital as the study site and to the staff at Clinic 5 for their assistance during data collection.

\section{REFERENCES}

1. Moser M, Roccella EJ. The treatment of hypertension: A remarkable success story. J Clin Hypertens (Greenwich) 2013;15:88-91.

2. D'souzai SJ, Mani A, Kurian N, Jaikanth C. Assessment of professional's adherence to joint national committee 8 guidelines in the management of hypertension. Asian J Pharm Clin Res 2019;12:101-5.

3. Kovell LC, Ahmed HM, Misra S, Whelton SP, Prokopowicz GP, Blumenthal RS, et al. US hypertension management guidelines: A review of the recent past and recommendations for the future. J Am Heart Assoc 2015;4:e002315.

4. World Health Organisation. Global Health Observatory (GHO) Data on Raised Blood Pressure, Situation and Trends. Geneva: World Health Organisation; 2019. Available from: https://www.who.int/gho/ncd/ risk factors/blood pressure text/en. [Last accessed on 2019 Jun 23].

5. Cushman WC, Whelton PK, Fine LJ, Wright JT Jr., Reboussin DM, Johnson $\mathrm{KC}$, et al. SPRINT trial results: Latest news in hypertension management. Hypertension 2016;67:263-5.

6. World Health Organization. Cardiovascular Diseases (CVDs): Key Facts. Geneva: World Health Organization; 2017. Avialable from: https:/www.who.int/news-room/fact-sheets/detail/cardiovasculardiseases-(cvds). [Last accessed on 2019 Jun 23].

7. Ghana Medical Association. Cardiovascular Diseases at Alarming Levels; Communiqué Issued at the $58^{\text {th }}$ Conference at Ho, Ghana; 2016. Available from: http://www.myjoyonline. [Last accessed on 2019 Jun 23].

8. Ghana Health Service. The Health Sector in Ghana: Facts and Figures. Accra, Ghana: Ghana Health Service; 2018. Available from: https:// www.ghanahealthservice.org/downloads/facts+figures_2018.pdf. [Last accessed on 2019 Jun 23].

9. Orduñez-Garcia P, Munoz JL, Pedraza D, Espinosa-Brito A, Silva LC, Cooper RS. Success in control of hypertension in a low-resource setting: The Cuban experience. J Hypertens 2006;24:845-9.

10. Joffres M, Falaschetti E, Gillespie C, Robitaille C, Loustalot F, Poulter N, et al. Hypertension prevalence, awareness, treatment and control in national surveys from England, the USA and Canada, and correlation with stroke and ischaemic heart disease mortality: A crosssectional study. BMJ Open 2013;3:e003423.

11. Kudo N, Yokokawa H, Fukuda H, Sanada H, Miwa Y, Hisaoka T, et al. Achievement of target blood pressure levels among Japanese workers with hypertension and healthy lifestyle characteristics associated with therapeutic failure. PLoS One 2015;10:e0133641.

12. Sanuade OA, Boatemaa S, Kushitor MK. Hypertension prevalence, awareness, treatment and control in Ghanaian population: Evidence from the Ghana demographic and health survey. PLoS One 2018; 13:e0205985.

13. Dosoo DK, Nyame S, Enuameh YA, Ayetey H, Danwonno H, Twumasi M, et al. Prevalence of hypertension in the middle belt of Ghana: A community-based screening study. Int J Hypertens 2019;2019:1089578.

14. Standard Treatment Guidelines. Republic of Ghana Ministry of Health. $7^{\text {th }}$ ed. Ghana: Yamens Press Ltd.; 2017.

15. Armstrong C, Joint National Committee. JNC8 guidelines for the management of hypertension in adults. Am Fam Physician 
2014;90:503-4.

16. Nwabuo CC, Dy SM, Weeks K, Young JH. Factors associated with appointment non-adherence among African-Americans with severe, poorly controlled hypertension. PLoS One 2014;9:e103090.

17. Akinniyi AA, Olamide OO. Missed medical appointment among hypertensive and diabetic outpatients in a tertiary healthcare facility in Ibadan, Nigeria. Trop J Pharm Res 2017;16:1417-24

18. Ogedegbe G, Schoenthaler A, Fernandez S. Appointment-keeping behavior is not related to medication adherence in hypertensive African Americans. J Gen Intern Med 2007;22:1176-9.

19. Katsouli A, Pandey T, Goldberg D. Abstract 54: An assessment of hypertension care and consistency of blood pressure control in a general medical clinic. Circ Cardiovasc Qual Outcomes 2012;5 Suppl 1:A54.

20. Wolf-Maier K, Cooper RS, Kramer H, Banegas JR, Giampaoli S, Joffres MR. et al. Hypertension treatment and control in five European countries, Canada, and the United States. Hypertension 2004;43:10-7.

21. Banegas JR, López-García E, Dallongeville J, Guallar E, Halcox JP, Borghi C. et al. Achievement of treatment goals for primary prevention of cardiovascular disease in clinical practice across Europe: The EURIKA study. Eur Heart J 2011;32:2143-52.

22. Schmieder RE, Gitt AK, Koch C, Bramlage P, Quarrak T, Tschope D. Achievement of individualized treatment targets in patients with comorbid Type-2 diabetes and hypertension: 6 Months results of the dialogue registry. BMC Endocr Disord 2015;15:23.

23. Muleta S, Melaku T, Chelkeba L, Assefa D. Blood pressure control and its determinants among diabetes mellitus co-morbid hypertensive patients at Jimma University medical center, South West Ethiopia. Clin
Hypertens 2017;23:29.

24. Noubani A, Nasreddine L, Sibai AM, Tamim H, Isma'eel H, Hussain I. Prevalence, awareness, and control of hypertension in Greater Beirut area, Lebanon. Int J Hypertens 2018;2018:5419861.

25. Nwankwo T, Yoon SS, Burt V, Gu Q. Hypertension among adults in the United States: National health and nutrition examination survey, 20112012. NCHS Data Brief 2013;133:1-8

26. Lionakis N, Mendrinos D, Sanidas E, Favatas G, Georgopoulou M. Hypertension in the elderly. World J Cardiol 2012;4:135-47.

27. Choi HM, Kim HC, Kang DR. Sex differences in hypertension prevalence and control: Analysis of the 2010-2014 Korea national health and nutrition examination survey. PLoS One 2017;12:e178334.

28. Sandberg K, Ji H. Sex differences in primary hypertension. Biol Sex Differ 2012;3:7

29. Everett B, Zajacova A. Gender differences in hypertension and hypertension awareness among young adults. Biodemography Soc Biol 2015;61:1-17.

30. Dharan DR, Moly Kt. Factors influencing compliance to therapeutic regimen among patients with hypertension. Asian J Pharm Clin Res 2017;10:286-9.

31. Frank J. Managing hypertension using combination therapy. Am Fam Physician 2008;77:1279-86.

32. Williams SK, Ravenell J, Seyedali S, Nayef S, Ogedegbe G. Hypertension treatment in blacks: Discussion of the U.S. clinical practice guidelines. Prog Cardiovasc Dis 2016;59:282-8.

33. Guerrero-García C, Rubio-Guerra AF. Combination therapy in the treatment of hypertension. Drugs Context 2018;7:212531. 